
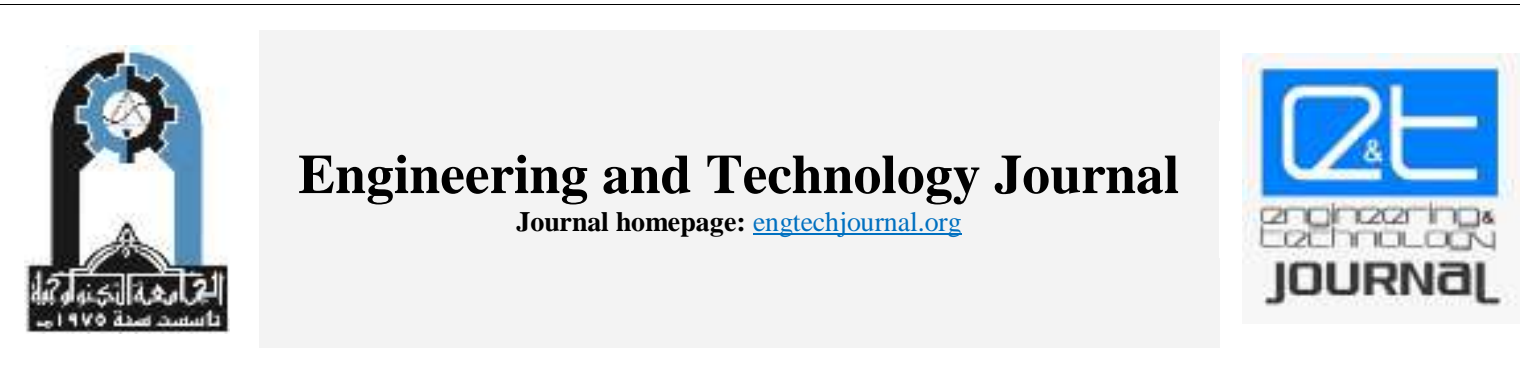

\title{
Diffraction Rings Pattern and Nonlinear Optical Properties of Hybrid ZnO-NPs / Epoxy Resin
}

\author{
Zahraa M. AL-Asady a*, Ali H. AL-Hamdani \\ ${ }^{a}$ Department of Laser and Optoelectronic Engineering, University of Technology, Iraq-Baghdad. \\ xzalasady5@gmail.com \\ Department of Laser and Optoelectronic Engineering, University of Technology, Iraq-Baghdad \\ *Corresponding author.
}

Submitted: 01/09/2019

Accepted: 21/12/2019

Published: 25/03/2020

K E Y W O R D S

UV-Vis absorption, Diffraction rings pattern technique, Z-scan technique and nonlinear optical properties.

\begin{abstract}
A B S T R A C T
In this research, the diffraction ring patterns scan and single-beam Z-scan techniques were used to measure the nonlinear refractive index $\left(n_{2}\right)$ and nonlinear absorption coefficient ( $\beta)$. Nano-composite sample, which consists of zinc oxide nanoparticles ( $\mathrm{ZnO}-\mathrm{NPs})$, and epoxy resin polymer. The sample was prepared by the casting method. A second harmonic generation Nd: YAG laser, which operates at $532 \mathrm{~nm}$ and intensity 3183 $W / \mathrm{cm}^{2}$ was used for the two techniques. Z-scan results showed that values for nonlinear refractive index $n_{2}$ and nonlinear absorption coefficient $\beta$ were obtained of $6.59 * 10^{-9} \mathrm{~cm}^{2} / W$ and $1.75 * 10^{-3} \mathrm{~cm} / W$ respectively. While results for the $D$-scan technique showed that the number of rings increases with the increasing of laser power.
\end{abstract}

How to cite this article: Z. M. AL-Asady and A. H. AL-Hamdani, "Diffraction rings pattern and nonlinear optical properties of hybrid ZnO-NPs / epoxy resin,” Engineering and Technology Journal, Vol. 38, Part A, No. 03, pp. 440-445, 2020.

DOI: https://doi.org/10.30684/etj.v38i3A.549

This is an open access article under the CC BY 4.0 license http://creativecommons.org/licenses/by/4.0.

\section{Introduction}

Recently, technological and scientific interest are focused on polymer nano-composites, because of their photonic applications like optical switching and optical limiting devices [1]. Those nano-composites are a type of combined material that consists of relatively small nanoparticles at nanometer-sized, which are dispersed in a polymer of uniform shape [2]. The mixing of polymer and nanoparticles will offer materials with better properties such as optical, thermal, electrical, mechanical, and many other properties [3]. Through the successful mixing of materials, which have various properties, a single material with new properties is obtained, which are used to provide material with high performance and excellence in many different scientific fields. The optical properties of nano-composites obtained very interesting because they are different from single polymers, also they give new properties which extremely from that the traditional materials [4]. The size of nanoparticles is considered an important factor, which is an effect on many optical properties of materials [2]. In the last years, great interests in the nonlinear properties of dyes and their mixture of polymers were occured [5, 6]. In addition, the existence of nano-particle in 
homogeneous composites change their optical properties [1]. In this paper, used transparent epoxy resins as polymer, because having several good specifications such as excellent transparency, low cost, lightweight, solidifies at room temperature, resistant to moisture and chemicals, so it is used a lot in the industry LED, optoelectronics, packaging materials, and others fields [7].

The zinc oxide powder as nanoparticles at dimension between 1-100nm, it is one of the groups of II-VI semiconductors and have important distinction as long-term environmental stability, low cost, non-toxic [1]. The zinc oxide nanoparticles was widely used in the medical field, optoelectronic devices of low wavelengths, such as light-emitting diodes (LED) and UV laser diode. ZnO-NPs was considered as an excellent candidate of different applications, like photo-catalysts, photo-detector, nano-generators, gas and biosensors, and solar cell [8]. Zinc oxide $(\mathrm{ZnO})$ is a well-known multifunctional inorganic filler that has unique properties such as strong UV absorption combine with good transparency in the visible range [9]. There are many techniques for measuring nonlinear optical properties of materials such as diffraction ring patterns, Z-scan, and thermal lens. These techniques are easy, simple and accurate measurements [10-12]. In this research, we will calculate the nonlinear refractive index (n2), nonlinear absorption coefficient $(\beta)$ and the total change in refractive index $(\Delta \mathrm{n})$ by using the two techniques.

\section{Experimental Work}

\section{Preparation $\mathrm{ZnO}-\mathrm{NPs} /$ Epoxy resin sample}

The zinc oxide nanoparticles (ZnO-NPs) are nano-white powder supplied by (US Research Nanomaterials, Inc. in the USA), have a molecular weight $(81.83 \mathrm{~g} / \mathrm{mol})$, purity $(98 \%)$ and particle size $(35-45)$ nm. Transparent epoxy (polyprime EP, A and B) was purchased from (Henkel Polybit Industries Ltd. in UAE). Ethanol solvent $(\mathrm{C} 2 \mathrm{H} 5 \mathrm{OH})$ is a colorless liquid supplied by (Gainland Chemical Company, factory road, U.K.), has a molecular weight $(46.07 \mathrm{~g} / \mathrm{mol})$ and purity $(99.9 \%)$. In this experiment, first, a certain weight of zinc oxide nanoparticles were measured by an electrical balance device (Radwag, AS $220 / \mathrm{C} / 2$, EU) having a sensitivity of $10-4 \mathrm{~g}$. The weight of the nanoparticle is $(0.015) \mathrm{g}$, then these nanoparticles were melted in $(10 \mathrm{ml})$ from ethanol. The mixture was placed under continuous stirring by a magnetic stirrer device to totally dissolve the zinc oxide nanoparticles. After that, a concentration of $(1 * 10-4) \mathrm{mol} / \mathrm{L}$ was taken from the original solution. The epoxy resin consists of two materials, the hardener (B) and the resin (A), these materials are added by (A: B) (3:1). Add the solution into the hardener (B) and resin (A) in a plastic box and mixed them well. Finally, the mixture was poured into the molds and leaves to harden at room temperature for three days.

\section{II. $U V$ - visible spectroscopic test}

A double-beam UV-Visible spectrophotometer (Thermo, biomate 5) was used to measure the absorption spectrum for $\mathrm{ZnO}-\mathrm{NPs}$ hybrid Epoxy resin nanocomposite. This device operates in the visible and ultraviolet region in the range of (190-1100) $\mathrm{nm}$. The absorption data and sample thickness can be used to calculate the absorption coefficient of the sample at different wavelengths.

\section{The nonlinear optical properties techniques}

1) Diffraction rings pattern technique (D-scan)

The experimental setup consists of second harmonic generation Nd: YAG laser at a wavelength (532) nm, glass convex lens with focal length $(10 \mathrm{~cm})$ used to focus the laser beam on the nano-composite sample with thickness $(0.7 \mathrm{~mm})$, pinhole aperture is $(0.5) \mathrm{mm}$, screen was placed away from the focal point and finally, CCD camera to record the diffraction rings. Figure 1 shows the setup for the D-scan technique.

2) Single beam Z-scan technique (Z-scan)

The Z-scan technique is a simple and effective method for determining the nonlinear optical properties $\mathrm{n} 2$ and $\beta$ of the sample (solids, liquids, and liquid solution). In this method, used a SHG Nd: YAG laser with wavelength $532 \mathrm{~nm}$ and power $100 \mathrm{~mW}$, which has intense enough to study nonlinearities in a sample, convex lens with $(10 \mathrm{~cm})$ focal length to focus the laser beam on the sample, the sample moves through the focal point $(\mathrm{z}=0)$ of the lens, pinhole with aperture $(1 \mathrm{~mm})$ use to provide a fixed or adjustable aperture through which laser beams may be directed and detector used to measure the input and output power of the laser. Adjust the laser power on $(80 \mathrm{mw})$, moved the sample through the axis of the incident 
beam (z-direction) respect to the focal point and observation the change in the intensity of the laser which measurement by a photo-detector. The nonlinear properties of the sample appear when the incident laser beam has sufficient energy to induce nonlinearity in the sample, so either convene the beam this case called (self-focusing) or spread the beam (self-defocusing). There are two methods of z-scan; closedaperture and open-aperture. the closed aperture can be determined by the nonlinear refractive index (n_2) while the nonlinear absorption coefficient $(\beta)$ determined by the open aperture. Figure 2 shows the z-scan setup.

\section{Results and Discussion}

\section{Spectral properties of the sample}

The UV-Vis absorption spectrum for the nano-composites sample (ZnO-NPs / epoxy resin) was shown in Figure 3. This spectrum indicates that the absorption peak is strong in the wavelength (375) $\mathrm{nm}$ and appears low absorption light in the visible region and high absorption in UV region (300-400) nm, which makes it convenient for medical applications like sunscreen protectors.

The absorption coefficient $(\alpha 0)$ was obtained directly by using the following Eq. (1) [13]:

$$
\alpha 0=2.303 \mathrm{~A} / \mathrm{d}
$$

Where $\mathrm{A}$ is the absorption peak and $\mathrm{d}$ is the sample thickness.

The value of the absorption coefficient calculates by using Eq. (1), where the value was $(12.35 \mathrm{~cm}-1)$ at the wavelength $(375 \mathrm{~nm})$ of nano-composites $\mathrm{ZnO}$-NPs /epoxy at the concentration for $\mathrm{ZnO}-\mathrm{NPs}(1 * 10-4$ ) $\mathrm{mol} / \mathrm{L}$.

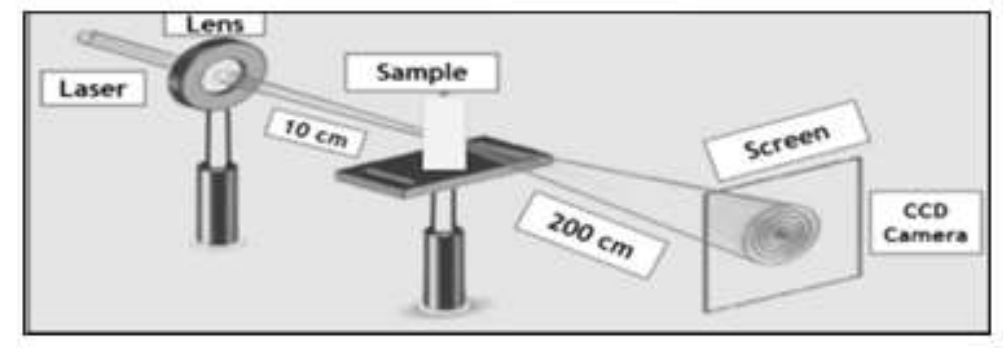

Figure 1: The experiment setup for D-scan technique

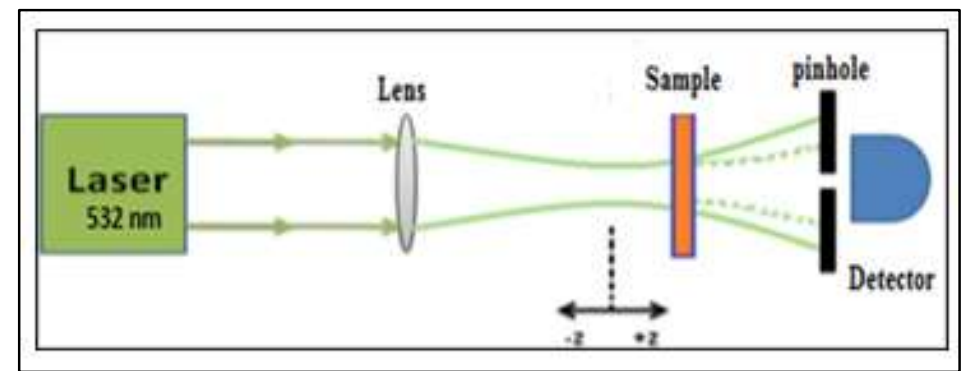

Figure 2: The experimental setup for Z-scan technique

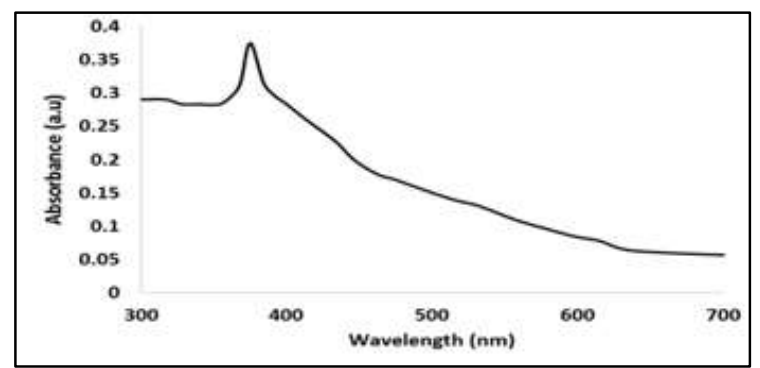

Figure 3: UV-Vis absorption spectra for $\mathrm{ZnO}-\mathrm{NPs}$ hybrid epoxy resin at $(1 * 10-4) \mathrm{mol} / \mathrm{L}$

II. Nonlinear optical properties measurements 
1) Diffraction scans measurement

By using the experimental setup shown above and the input powers for laser $(50,60,70,80$, and 90$) \mathrm{mW}$. The diffraction rings appear immediately and noticed that the numbers of rings increasing when increasing the input power laser, this can be seen in Figure 4.

Calculate the nonlinear refractive index (n2) and change in refractive index $(\Delta \mathrm{n})$ for the sample by using the following Eqs. (2) and (3) [14]:

$\mathrm{n} 2=\Delta \mathrm{n} / \mathrm{I}$

$\Delta \mathrm{n}=\lambda \mathrm{N} / \mathrm{L}$

Where $\mathrm{I}$ is input intensity laser, $\lambda$ is wavelength laser, $\mathrm{N}$ is the number of rings and $\mathrm{L}$ is the thickness of the sample. For $\lambda=532 \mathrm{~nm}, \mathrm{~L}=0.7 \mathrm{~mm}$ and input power $(50,60,70,80$ and 90$) \mathrm{mW}$, the values for (n2) and $(\Delta \mathrm{n})$ given in Table 1 .

\section{2) Z-scan measurement}

The nonlinear refractive index (n2) of nano-composite (ZnO-NPs/ epoxy resin) was measured under a closed- aperture arrangement. Figure 5 shows the closed aperture z-scan transmittance curve. The valley to peak structure of close aperture curve, it illustrates the nano-composite ZnO-NPs/epoxy has the positive nonlinear refractive feature (self-focusing).

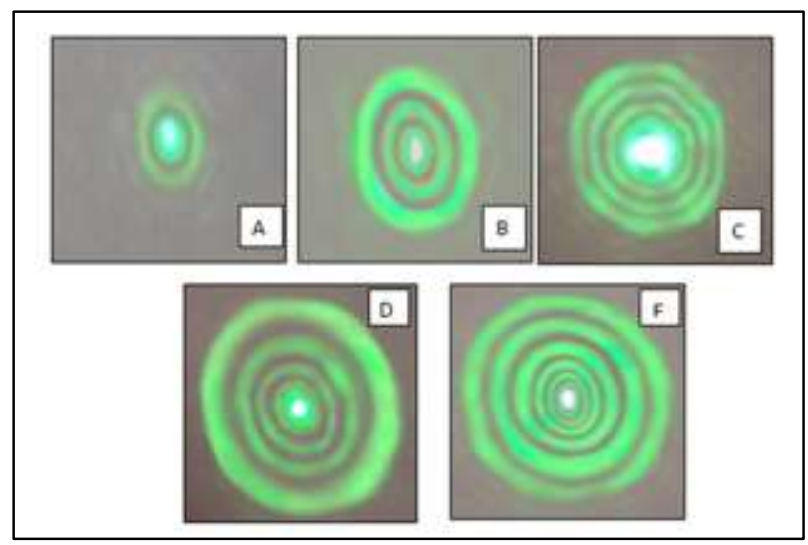

Figure 4: The images of diffraction rings with different input power (A) $50 \mathrm{~mW}$ (B) $60 \mathrm{~mW}$ (C) $70 \mathrm{~mW}$ (D) $80 \mathrm{~mW}$ (E) $90 \mathrm{~mW}$

Table 1: The magnitudes of the nonlinear refractive index and change refractive index for $\mathrm{ZnO}$-NPs hybrid epoxy resin

\begin{tabular}{lllc}
\hline \hline Power $\mathrm{mW}$ & No. of rings & $\mathrm{n}_{2} * 10^{-6} \mathrm{~cm}^{2} / \mathrm{W}$ & $\Delta \mathrm{n}^{*} 10^{-3}$ \\
\hline 50 & 1 & 0.382 & 0.76 \\
& & & \\
\hline 60 & 2 & 0.636 & 1.52 \\
\hline 70 & 3 & 0.818 & 2.28 \\
\hline 80 & 4 & 0.955 & 3.04 \\
\hline 90 & 5 & 1.06 & 3.8 \\
\hline
\end{tabular}

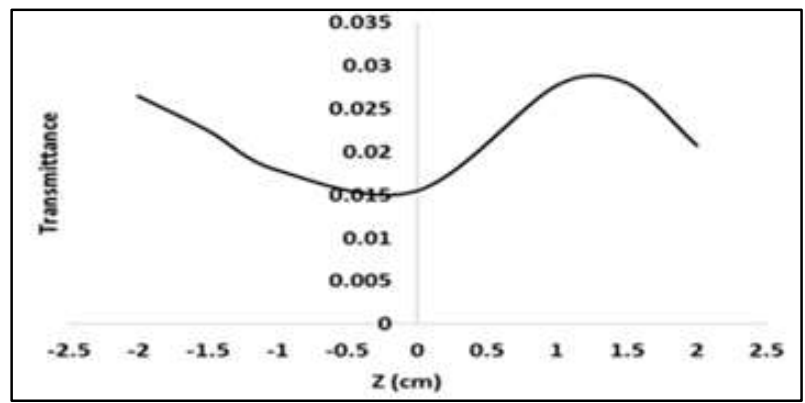


Figure 5: The close Z-scan data for nanocomposite $\mathrm{ZnO}-\mathrm{NPs} / \mathrm{epoxy}$ at $(1 * 10-4) \mathrm{mol} / \mathrm{L}$

The nonlinear refraction index is calculated from the difference between the peak and valley of the transmittance experimentally by the following Eq. (4) [15]:

$n_{2}=\frac{\Delta \emptyset_{0} \lambda}{2 \pi I_{0} L_{e f f}}$

Where $\Delta \emptyset_{0}$ is nonlinear phase shift, $\lambda$ is wavelength laser, $\mathrm{I}_{0}$ is the laser intensity and $\mathrm{L}_{\text {eff }}$ is the effective length of the sample, which can determine from Eq. (5) [16]:

$L_{\text {eff }}=\frac{1-e^{-\alpha L}}{\alpha}$

Where $L$ is the sample thickness and $\alpha$ is linear absorption coefficient.

The nonlinear absorption coefficient $(\beta)$ for nano-composite ZnO-NPs/epoxy was estimated under open aperture arrangement. Figure 6 shows the open aperture z-scan transmittance .The curve shows the nonlinear effective region is extended from $(2 \mathrm{~cm})$ to $(-2 \mathrm{~cm})$ and maximum value at $\mathrm{Z}=0$, which indicated the nonlinear absorption coefficient $(\beta)$ is saturated absorption.

The nonlinear optical absorption coefficient is obtained from the following Eq. (6) [17]

$\beta=\frac{2 \sqrt{2} \Delta T}{I_{0} L_{e f f}}$

Where $\Delta \mathrm{T}$ is the peak transmittance value in the open aperture $\mathrm{Z}$-scan curve, $\mathrm{L}_{\text {eff }}$ is the effective thickness of the sample.

The nonlinear refractive index $\mathrm{n} 2(\mathrm{~cm} 2 / \mathrm{W})$ and nonlinear absorption coefficient $\beta(\mathrm{cm} / \mathrm{W})$ for sample (ZnO-NPs/ epoxy) were calculated from equations (4) and (6). Their values are listed in Table 2.

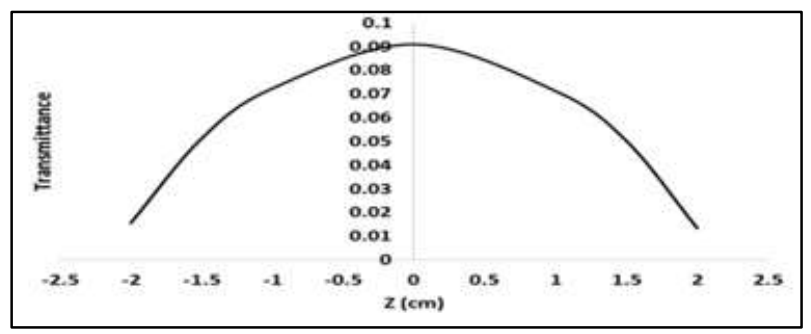

Figure 6: The open Z-scan data for nanocomposite $(\mathrm{ZnO}-\mathrm{NPs} /$ epoxy) at $(1 * 104) \mathrm{mol} / \mathrm{L}$

Table 2: The nonlinear optical parameters for (ZnO-NPs/epoxy) at $80 \mathrm{~mW}$ power laser

\begin{tabular}{llll}
\hline \hline Sample & $\begin{array}{l}\text { Linear absorption } \\
\text { coefficient } \alpha \\
\left(\mathrm{cm}^{-1}\right)\end{array}$ & $\begin{array}{l}\text { Nonlinear absorption coefficient } \beta \\
(\mathrm{cm} / \mathrm{W})\end{array}$ & $\begin{array}{l}\text { Nonlinear refractive } \\
\text { index } \mathrm{n}_{2} \\
\left(\mathrm{~cm}^{2} / \mathrm{W}\right)\end{array}$ \\
\hline $\begin{array}{l}\mathrm{ZnO}-\mathrm{NPs} \\
\text { lepoxy }\end{array}$ & 12.35 & $1.75^{*} 10^{-3}$ & $6.59^{*} 10^{-9}$ \\
\hline
\end{tabular}

\section{Conclusion}

In summary, transparent (ZnO-NPs/epoxy resin) nano-composite with high UV light-shielding efficiency was reported in this research. In the diffraction rings technique, it has been noticed the appearance of several rings when passing the visible laser $(\mathrm{CW})$ beam through the sample. At power laser $(90 \mathrm{~mW})$, it has been observed 5 rings for the nano-composite sample. The results for D-scan show the linearly proportionality between the numbers of rings and the intense laser light when the intensity is increased the diffraction rings also increasing. It has been getting large values for nonlinear refractive index $\mathrm{n} 2=1.06$ $* 10-6(\mathrm{~cm} 2 / \mathrm{W})$ by diffraction scan technique. Also was measured the nonlinear optical properties $(\mathrm{n} 2$ and $\beta$ ) for nano-composite $\mathrm{ZnO}-\mathrm{NPs} /$ epoxy by using the single-beam Z-scan technique at the wavelength laser $532 \mathrm{~nm}$.

The results show that $\mathrm{ZnO}-\mathrm{NPs} /$ epoxy sample behavior self-focusing nonlinearities. This transparent (ZnO-NPs/epoxy) sample was considered as a great candidate for many engineering applications like windows for vehicles and parts for precision optical devices.

\section{References}


[1] H. M. Shanshool, "Linear and nonlinear optical properties of polymer-Zno-Cuo nanocomposites," Ph.D. Thesis, Dept. Science and Technology, Univ. Kebangsaan, Bangi, Malaysia, 2016.

[2] S. Li, L. M. Meng and S. M. Toprak, "Nanocomposites of polymer and inorganic nanoparticles for optical and magnetic applications,” Nano Reviews, Vol.1, pp.1-19, Apr. 2010.

[3] A. Anžlovar, K. Kogej, Z. Crnjak Orel and M. Žigon, "Polyol mediated nano size zinc oxide and nanocomposites with poly (methyl methacrylate),” eXPRESS Polymer Letters, Vol.5, pp. 604-619, Jan. 2011.

[4] A. P. Indolia and M. S. Gaur, "Optical properties of solution grown PVDF-ZnO nanocomposite thin films," Journal of Polymer Research, Vol.20, pp.1-8, Dec. 2012.

[5] H. Ali Al-Hamdani, S. Adnan Al-Ethawi and R. Al-Hamdani, "Fluorescence efficiency of rhodamine 6G doped PMMA,” Journal of materials sciences and engineering, Vol.4, pp.57-61, Oct. 2010.

[6] H. A. AL-Hamadani and N. Al-Ansari, "nonlinear optical properties of deoxyribonucleic acid DNA doped Rhodamine B/PVA films using Z-scan technique," International Journal of Current Engineering and Technology, Vol.7, pp.1802-1804, Oct., 2017.

[7] JC. Huang, YP. Chu, M. Wei and RD. Deanin, "Comparison of epoxy resins for applications in light-emitting diodes,” Adv. Polymer Techno, Vol.23, pp.298-306, 2004.

[8] Y. L. A. and H. M. U. Ozgur, “a comprehensive review of ZnO materials and devices,” Journal Applied Physics, Vol. 98, pp. 1-103, 2005.

[9] M. M. Demir, K. Koynoy, C. Bubeck and G. Wegner, "Optical properties of composite of PMMA and surface modified zincite nanoparticles," Macromolecules, Vol. 40, pp. 1089-1100, 2007.

[10] K. Ogusu, Y. Kohtani and H. Sao, "laser induced diffraction rings from an absorbing colution," Opt. Rev., Vol. 3, pp. 232-234, 1996.

[11] M. Sheik-Bakae, A.A. Said, T.H. We, D.J. Hegan and E.W. Van Styland, "Sensitive measurement of optical nonlinearities using a single beam,” IEEE J. Quant. Electron, Vol. 26, pp.760-769, Apr. 1990.

[12] R. Zamiri, R. Parvizi, A. Zakaria, A.R. Sadrolhosseini, G. Zamiri, M. Darrouds and M.S. Hus, "Investigation on nonlinear-optical properties of palm oil/Silver nano- Particles,” J.Europ. Opt. Soc. Rap. Public. , Vol.7, pp.120204, June 2012.

[13] F. Yakuphanoglu, S. Ilican, M. Caglar and Y. Caglar, , "The determination of the optical band and optical constants of non-crystalline and crystalline $\mathrm{ZnO}$ thin films deposited by spray pyrolysis," Journal of optoelectronics and advanced materials, Vol. 9, pp. 2180-2185, July, 2007.

[14] M. Qusay Ali Hassan, H. Sultan, H. Bakr, "Diffraction patterns and nonlinear optical properties of Henna oil," Journal of College of Education for pure sciences, Vol.7, pp.1-15, Dec. 2017.

[15] M. Dinu, F. Quochi, and H. Garcia, "Third-order nonlinearities in silicon at telecom wavelengths," Applied physics letters, Vol.82, pp.1954-2956, 2003.

[16] A. F. Jaffar, "Nonlinear characterization of rhodamine 610 dye-doped PMMA thin films under $650 \mathrm{~nm}$ CW laser light excitation,” Journal of Al-Nahrain University, Vol. 17, pp. 95-102, 2014.

[17] G. Vinitha and A. Ramalingam, "Third-order optical nonlinearities and optical limiting properties of a pararosanilin dye liquid and solid media," Las. Phys., Vol. 18, pp. 1070-1073, 2008. 